\title{
Is obstructive sleep apnoea associated with hypoxaemia and prolonged ICU stay after type A aortic dissection repair? A retrospective study in Chinese population
}

\author{
Xin $\mathrm{Xi}^{1,2+}$, Yu Chen ${ }^{3+}$, Wei-Guo Ma ${ }^{3}$, Jiang Xie ${ }^{2^{*}} \mathbb{0}$, Yong-Min Liu ${ }^{3}$, Jun-Ming Zhu ${ }^{3}$, Ming Gong ${ }^{3}$, \\ Guang-Fa Zhu ${ }^{2}$ and Li-Zhong Sun ${ }^{3}$
}

\begin{abstract}
Background: Although obstructive sleep apnoea (OSA) is prevalent among patients with aortic dissection, its prognostic impact is not yet determined in patients undergoing major vascular surgery. We aimed to investigate the association of OSA with hypoxaemia and with prolonged intensive care unit (ICU) stay after type A aortic dissection (TAAD) repair.

Methods: This retrospective study continuously enrolled 83 patients who underwent TAAD repair from January 1 to December 31,2018. OSA was diagnosed by sleep test and defined as an apnoea hypopnea index (AHI) of $\geq 15 / h$, while an $\mathrm{AHI}$ of $>30 / \mathrm{h}$ was defined severe OSA. Hypoxaemia was defined as an oxygenation index (OI) of $<200 \mathrm{mmHg}$. Prolonged ICU stay referred to an ICU stay of $>72 \mathrm{~h}$. Receiver operating characteristic curve analysis was performed to evaluate the predictive value of postoperative OI for prolonged ICU stay. Multivariate logistic regression was performed to assess the association of OSA with hypoxaemia and prolonged ICU stay.

Results: A total of 41 (49.4\%) patients were diagnosed with OSA using the sleep test. Hypoxaemia occurred postoperatively in 56 patients (67.5\%). Postoperatively hypoxaemia developed mostly in patients with OSA (52.4\% vs. 83.0\%, $p=0.003)$, and particularly in those with severe OSA $(52.4 \%$ vs. $90.5 \%, p=0.003)$. The postoperative Ol could fairly predict a prolonged ICU stay (area under the receiver-operating characteristic curve, $0.72 ; 95 \%$ confidence intervals $[\mathrm{Cl}]$ 0.60-0.84; $p=0.002$ ). Severe OSA was associated with both postoperative hypoxaemia (odds ratio [OR] 6.65; 95\% Cl 1.56-46.26, $p=0.008$ ) and prolonged ICU stay (OR 5.58; 95\% Cl 1.54-20.24, $p=0.009$ ).
\end{abstract}

Conclusions: OSA was common in patients with TAAD. Severe OSA was associated with postoperative hypoxaemia and prolonged ICU stay following TAAD repair.

Keywords: Obstructive sleep apnoea, Aortic dissection, Hypoxaemia, Intensive care unit

*Correspondence: frank782008@aliyun.com

${ }^{\dagger} \mathrm{Xin} \mathrm{Xi}$ and $\mathrm{Yu}$ Chen have contributed equally to this work

2 Department of Respiratory and Critical Medicine, Beijing Anzhen

Hospital, Capital Medical University, No. 2 Anzhen Road, Beijing 100029,

China

Full list of author information is available at the end of the article

\section{Background}

Aortic dissection (AD) is a lethal disease in which the inner layer of the aorta tears. The Stanford classification divides AD into two groups, namely Type A aortic dissection (TAAD) and Type $B$ aortic dissection. TAAD results from pathological involvement of the ascending aorta and is associated with significant mortality and morbidity 
despite the numerous apparent improvements in diagnosis and management during the past six decades. Recent data from a study of 4428 patients between 1995 and 2013 show that the in-hospital and surgical mortality rates are still as high as $22 \%$ and $18 \%$ for patients with TAAD, even with modern medical and surgical/ endovascular therapies [1]. Noticeably, for patients with acute [2] or anterograde [3] AD, the fatality remains staggering even following surgical intervention. Therefore, identifying patients at high risk of operative mortality and morbidity will reduce TAAD-related mortality, thus improving its prognosis.

We found previously that hypoxaemia is a common complication in patients with TAAD, and could result in increased postoperative hypoxaemia [4]. Multiple factors could be associated with the development of hypoxaemia following TAAD repair, such as dissection-induced inflammatory response, cardiopulmonary bypass, lung atelectasis, and ischaemic reperfusion injury [4]. Postoperative hypoxaemia prolongs the duration of mechanical ventilation and intensive care unit (ICU) stay, and increases the chances of hospital-acquired pneumonia, reintubation and tracheostomy, and risk of death [4, 5]. Our previous studies showed that more than $30 \%$ of patients developed hypoxaemia following TAAD repair and that tracheal reintubation was required in $7.5 \%$ of the cases [4, 6-8]. Therefore, identification of the factors associated with postoperative hypoxaemia is essential for optimising treatment and improving patient survival following TAAD repair.

Studies have reported that obstructive sleep apnoea (OSA) is associated with the onset of aortic dissection through arterial dysfunction, hypertension, and augmented negative thoracic pressure [9-11]. Patients with OSA can have poor short-term prognosis as they are at risk of developing hypoxaemia following cardiac and non-cardiac surgeries [12-16]. However, the mechanism by which OSA affects the development of hypoxaemia and prolonged ICU stay in patients undergoing TAAD repair has not been fully elucidated. In this study, we sought to examine: 1) the prevalence of OSA in patients with TAAD, and 2) to evaluate the association of OSA with postoperative hypoxaemia and prolonged ICU stay following TAAD repair.

\section{Methods}

\section{Study design and patient enrolment}

This retrospective study was conducted in 252 consecutive patients with acute or chronic TAAD (either anterograde or retrograde subtype) who underwent total arch replacement between January 1 and December 31, 2018, at the Beijing Anzhen Hospital. TAAD was diagnosed using computed tomographic angiography in all the patients.

Patients would be excluded from this study due to one of the following conditions:

(1) diagnosed with OSA and treated by positive airway pressure before surgery,

(2) unsuccessful sleep tests owing to clinical concerns, i.e., haemodynamic instability, unbearable pain, severe anxiety, etc.,

(3) slept for less than $4 \mathrm{~h}$ in the evening of the sleep test owing to insomnia or unbearable pain, and

(4) declined to take the sleep test.

A total of 124 patients completed the sleep test and 83 of them had complete sleep data and answered the STOP-BANG questionnaire [17]. These 83 patients were included in the final analysis (Fig. 1).

\section{Sleep study}

OSA was diagnosed via completing sleep test within 90 days following surgical procedure. Nox T3 devices (Nox Medical, Reykjavík, Iceland) were used to perform the sleep tests, and an acceptable sleep test should contain a total sleep time $>5 \mathrm{~h}$. Recorded electrodes included nasal pressure transducers, thoracic and abdominal plethysmography, cardiac pulse, snoring, body position, activity, and percutaneous oxygen saturation.

According to the detection of a nasal airflow transducer, apnoea was defined by breath cessation or $\geq 90 \%$ airflow drop that lasted longer than $10 \mathrm{~s}$, while hypopnea was verified by at least $30 \%$ decline in airflow that lasted longer than $10 \mathrm{~s}$ and was accompanied by a $3 \%$ decrease in oxygen saturation. Apnoea hypopnea index (AHI) was defined as the sum of apnoea and hypopnea per hour. OSA was diagnosed when the AHI was $15 / \mathrm{h}$ or more, and

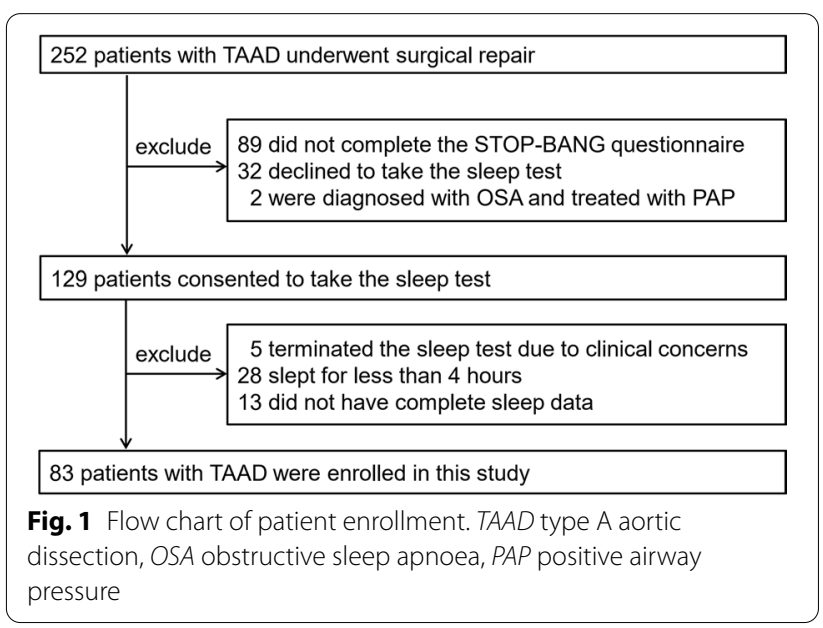


severe OSA was defined by an AHI greater than 30/h. Hypoxaemia during sleep was determined by the average oxygen saturation, the nadir nocturnal oxygen saturation, the percentage of time with oxygen saturation of $<90 \%$, and the oxygen desaturation index (i.e., oxygen saturation drop by $\geq 3 \%$ per hour). Daytime sleepiness was calculated using the Epworth Sleepiness Scale (ESS) [18].

Although not accepted as a diagnostic tool, the STOPBANG score was completed [17] routinely on admission. Patients were assessed by answering "yes" or "no" to eight questions related to major subjective and objective manifestations of OSA. The sum of scores ranged from 0 to 8 , and a modified STOP-BANG score of $\geq 4$ was considered a high risk of OSA [19]. The consistency of the STOPBANG score with the objective sleep test was calculated.

\section{Surgical management}

The indications and techniques of TAAD repair in our centre have been described in detail previously [20]. Briefly, it is performed under cardiopulmonary bypass with selective antegrade cerebral perfusion and involves deployment of a stented vascular graft into the descending aorta via hypothermic circulatory arrest, followed by total arch replacement using a four-branched graft.

\section{Data collection and definitions}

The duration of cardiopulmonary bypass, cross-clamp, antegrade cerebral perfusion, and the entire procedure as well as the amount of packed red blood cells transfused during surgery were collected. To evaluate the severity of the patients' perioperative desaturation, arterial blood was drawn $2 \mathrm{~h}$ before and $6 \mathrm{~h}$ after the surgical procedure, and the blood gas was assessed on-site promptly.

Preoperative and postoperative oxygenation indices (OIs) were calculated as the ratio of arterial partial oxygen/inspired oxygen fraction at $2 \mathrm{~h}$ before and at $6 \mathrm{~h}$ after the surgery. Preoperative or postoperative hypoxaemia was defined as an OI of $<200 \mathrm{mmHg}$ [21, 22]. Postoperative complications, a composite endpoint, included sepsis, pulmonary infection, cardiac dysfunction, acute renal failure, re-exploration for bleeding, surgical site infection, stroke, postoperative delirium, paraplegia or paralysis and gastrointestinal bleeding. Systolic blood pressure (BP) of $\geq 130 \mathrm{mmHg}$ or diastolic of $\geq 80 \mathrm{mmHg}$ were regarded as uncontrolled BP [23] Prolonged ICU stay was defined as $\mathrm{a} \geq 72 \mathrm{~h}$ stay in the ICU for any reason [24].

\section{Statistical analysis}

Normally distributed continuous variables verified by Shapiro-Wilk test are expressed as mean \pm standard deviation (SD), and were compared using the Student's $t$ test. Median and interquartile range (IQR) were used for skewed variables, which were compared using the
Wilcoxon test. Categorical variables are expressed as a number (percentage), and were compared using the Pearson's chi-square test or the Fisher's exact test. The kappa coefficient was calculated to evaluate the agreement between the preoperative STOP-BANG questionnaire score and postoperative sleep test in the diagnosis of OSA. Adjusted odds ratios (OR) and 95\% confidence intervals $(\mathrm{CI})$ were estimated from the multivariate logistic model to determine the relationship between the explanatory variables of preoperative hypoxaemia, OSA and AHI stratification, and response variables of postoperative hypoxaemia and prolonged ICU stay. Covariates included in the adjusted model were age, sex, and body mass index (BMI), which were the confounding variables considering their relevance to both OSA and aortic dissection $[25,26]$. A receiver-operating characteristic (ROC) curve was constructed to determine the optimal cut-off of postoperative OI that could predict prolonged ICU stay based on the value yielding the best combination of sensitivity and specificity. Statistical analysis was performed using SPSS 18.0 for Windows (SPSS Inc., Chicago, IL), and a two-tailed $p$-value of $<0.05$ was considered statistically significant.

\section{Results}

\section{Baseline characteristics}

This study enrolled 83 patients (66 [79.5\%] men, 74 [89.2\%] acute and 76 [91.6\%] anterograde TAAD). Among these, the diagnosis of OSA was confirmed by sleep test in 41 patients (49.4\%). Modified STOP-BANG score of $\geq 4$ to predict OSA also demonstrated high consistency with the objective sleep test (golden standard) $($ Kappa $=0.42, p<0.001)$. Besides having significantly higher scores of ESS and STOP-BANG, patients with OSA were more likely to have uncontrolled hypertension than those without OSA ( $95.1 \%$ vs. $78.6 \%, p=0.026)$ (Table 1).

Of the entire cohort, 56 patients developed postoperative hypoxaemia $(67.5 \%)$ and 22 patients $(26.5 \%)$ had prolonged ICU stay $(>72 \mathrm{~h}$ ). Patients with OSA vs. patients without OSA, were more likely to have incidence of postoperative hypoxaemia $(83.0 \%$ vs. $52.4 \%, p=0.003)$ and composite postoperative complications $(75.6 \%$ vs. $52.4 \%$, $p=0.028$ ), and showed significantly longer intubation time (24.6 h vs. $22.4 \mathrm{~h}, p=0.026)$ and ICU length of stay (54.0 h vs. $28.5 \mathrm{~h}, p=0.007$ ) after surgery (Table 2). As shown in Fig. 2, the ICU length of stay was significantly longer in patients with an AHI of $>30 / \mathrm{h}$ than in those with an AHI of $<15 / \mathrm{h}(62.0 \mathrm{~h}$ vs. $28.5 \mathrm{~h}, p=0.008)$.

\section{Factors associated with postoperative hypoxaemia}

Multivariate analysis (adjusted for age, sex, and BMI) showed that preoperative hypoxaemia and OSA were 
Table 1 Comparison of baseline characteristics of enrolled patients grouped by comorbid OSA

\begin{tabular}{|c|c|c|c|c|}
\hline \multirow[t]{2}{*}{ Variable } & \multirow[t]{2}{*}{ Total $(n=83)$} & \multicolumn{2}{|c|}{ Obstructive sleep apnoea } & \multirow[t]{2}{*}{$p$ value } \\
\hline & & Yes $(n=41)$ & No $(n=42)$ & \\
\hline Male gender & $66(79.5)$ & $32(78.0)$ & $34(81.0)$ & 0.743 \\
\hline Age (y) & $47.7 \pm 10.8$ & $50.3 \pm 9.7$ & $45.1 \pm 11.4$ & 0.023 \\
\hline Body mass index $\left(\mathrm{kg} / \mathrm{m}^{2}\right)$ & $25.8 \pm 3.8$ & $26.7 \pm 3.6$ & $24.9 \pm 3.9$ & 0.035 \\
\hline STOP-BANG score & $5.0(4.0,6.0)$ & $5.0(4.0,6.5)$ & $3.0(2.0,4.0)$ & 0.001 \\
\hline STOP-BANG score $\geq 4$ & $53(63.9)$ & $35(85.4)$ & $18(42.9)$ & $<0.001$ \\
\hline Epworth sleepiness scale & $7.0(4.0,12.0)$ & $10.0(5.0,12.0)$ & $4.5(3.0,9.8)$ & 0.004 \\
\hline Apnoea hypopnea index (events/h) & $13.8(5.8,30.2)$ & $30.2(20.5,48.3)$ & $5.9(3.0,9.4)$ & $<0.001$ \\
\hline Oxygen desaturation index (events/h) & $14.3(5.5,26.9)$ & $26.0(19.8,46.3)$ & $5.9(2.5,8.9)$ & $<0.001$ \\
\hline $\mathrm{MinSaO}_{2}(\%)$ & $78.7 \pm 11.1$ & $74.4 \pm 11.3$ & $82.9 \pm 9.2$ & 0.001 \\
\hline $\mathrm{MeanSaO}_{2}(\%)$ & $93.9 \pm 2.4$ & $93.1 \pm 2.3$ & $94.7 \pm 2.2$ & 0.005 \\
\hline $\mathrm{T} 0 \mathrm{SaO}_{2}(\%)$ & $2.0(0.2,7.4)$ & $5.2(1.3,18.3)$ & $0.35(0,2.7)$ & $<0.001$ \\
\hline Marfan syndrome & $9(10.8)$ & $2(4.9)$ & $7(21.8)$ & 0.156 \\
\hline Family history of aortic disease & $10(12.0)$ & $4(9.8)$ & $6(14.3)$ & 0.738 \\
\hline Uncontrolled hypertension & $72(86.7)$ & $39(95.1)$ & $33(78.6)$ & 0.026 \\
\hline Dyslipidemia & $23(27.7)$ & $13(31.7)$ & $10(23.8)$ & 0.422 \\
\hline Diabetes mellitus & $7(8.4)$ & $4(9.8)$ & $3(7.1)$ & 0.713 \\
\hline Chronic obstructive pulmonary disease & $11(13.3)$ & $8(19.3)$ & $3(7.1)$ & 0.097 \\
\hline Coronary heart disease & $11(13.3)$ & $5(12.2)$ & $6(14.3)$ & 0.779 \\
\hline Cerebrovascular accident & $9(10.8)$ & $5(12.2)$ & $4(9.5)$ & 0.738 \\
\hline Current smoker & $55(66.3)$ & $30(73.2)$ & $25(60.0)$ & 0.189 \\
\hline Bicuspid aortic valve & $2(2.4)$ & $0(0)$ & $2(4.8)$ & 0.494 \\
\hline Aortic regurgitation* & $31(37.3)$ & $14(34.1)$ & $17(40.5)$ & 0.551 \\
\hline Preoperative hypoxaemia & $39(47.0)$ & $20(48.8)$ & $19(45.2)$ & 0.746 \\
\hline Left ventricular ejection fraction (\%) & $62.5 \pm 5.2$ & $63.1 \pm 6.1$ & $62.0 \pm 4.2$ & 0.326 \\
\hline Pericardial effusiont & $50(60.2)$ & $29(70.7)$ & $21(46.1)$ & 0.054 \\
\hline
\end{tabular}

Data are expressed as mean \pm standard deviation, median (interquartile range) or $\mathrm{n}(\%)$

$\mathrm{MeanSaO}_{2}$, average oxygen saturation; $\mathrm{MinSaO}_{2}$, nadir nocturnal oxygen saturation; $\mathrm{T}_{90 \mathrm{SaO}}$, percentage of time with saturation lower than $90 \%$

*Including moderate-to-severe aortic regurgitation

${ }^{\dagger}$ Refers to pericardial effusion of $>100 \mathrm{ml}$

associated with postoperative hypoxaemia. Patients with an AHI $>30 / h$ had significantly higher odds of developing postoperative hypoxaemia vs. patients with an $\mathrm{AHI}<15 / \mathrm{h}$ (OR 3.28, 95\% CI 1.14-10.10, $p=0.028$ ) (Table 3).

\section{Factors associated with prolonged ICU stay}

With an overall area under the curve of 0.72 (95\% CI $0.60-0.84 ; p=0.002$ ) (ROC analysis showed that a postoperative OI of 133.25 was the optimal cut-off value for predicting prolonged ICU stay (sensitivity: 63.6\%; specificity: $75.4 \%$; accuracy: $48.3 \%$ ) (Fig. 3). When taken as a continuous variable, for every unit decrease in postoperative OI, the risk of prolonged ICU stay would be increased by $1 \%$ (OR 1.01; 95\% CI 1.00-1.02, $p=0.008$ ).

OSA was shown to be associated with prolonged ICU stay (unadjusted OR 3.84; 95\% CI 1.32-11.17, $p=0.010$; adjusted OR $4.05 ; \quad 95 \%$ CI 1.27-12.90, $p=0.018$ ) (Table 3). Furthermore, compared to an AHI of $<15 / \mathrm{h}$, an
AHI of $>30 / h$ (severe OSA) was also identified to be associated with prolonged ICU stay (OR 5.46; 95\% CI 1.6619.49, $p=0.005$ ), which persisted following adjustments for confounding variables (OR 5.60; 95\% CI 1.59-21.75, $p=0.009$ ) (Table 3).

\section{Discussion}

The results of this study show that OSA is prevalent in patients with TAAD, and severe OSA is predictive of postoperative hypoxaemia and prolonged ICU stay following TAAD repair. For patients with TAAD undergoing surgical repair, a sleep apnoea assessment with the STOP-BANG questionnaire prior to surgery could be helpful in recognising individuals who are at high risk of postoperative hypoxaemia and requiring perioperative intervention for OSA. 
Table 2 Comparison of operative and postoperative data for enrolled patients grouped by comorbid OSA

\begin{tabular}{|c|c|c|c|c|}
\hline \multirow[t]{2}{*}{ Variable } & \multirow[t]{2}{*}{ Total $(n=83)$} & \multicolumn{2}{|c|}{ Obstructive sleep apnoea } & \multirow[t]{2}{*}{$p$ value } \\
\hline & & Yes $(n=41)$ & No $(n=42)$ & \\
\hline \multicolumn{5}{|l|}{ Operative data } \\
\hline Cardiopulmonary bypass time (min) & $194.2 \pm 40.5$ & $194.4 \pm 33.0$ & $193.9 \pm 47.1$ & 0.951 \\
\hline Cross-clamp time (min) & $107.3 \pm 28.7$ & $108.1 \pm 26.1$ & $106.5 \pm 31.3$ & 0.778 \\
\hline Antegrade cerebral perfusion time (min) & $25.5 \pm 7.9$ & $25.7 \pm 8.8$ & $25.4 \pm 6.9$ & 0.871 \\
\hline Operative time (h) & $7.0(6.0,8.0)$ & $7.0(6.0,8.0)$ & $7.3(6.0,8.0)$ & 0.384 \\
\hline Transfused packed red blood cells (unit) & $0.0(0,4.0)$ & $2.0(0.0,4.0)$ & $0.0(0,4.0)$ & 0.398 \\
\hline \multicolumn{5}{|l|}{ Early surgical Outcomes } \\
\hline Postoperative hypoxaemia & $56(67.5)$ & $34(83.0)$ & $22(52.4)$ & 0.003 \\
\hline Total intubation time (h) & $23.3(20.0,45.0)$ & $24.6(21.5,47.5)$ & $22.4(19.1,25.5)$ & 0.026 \\
\hline Length of intensive care unit stay ( $h$ ) & $36.0(26.0,75.0)$ & $54.0(30.0,87.0)$ & $28.5(25.0,52.3)$ & 0.007 \\
\hline Prolonged intensive care unit stay ( $>72 \mathrm{~h}$ ) & $22(26.5)$ & $16(39.0)$ & $6(14.3)$ & 0.011 \\
\hline Composite postoperative complications* & $53(63.9)$ & $31(75.6)$ & $22(52.4)$ & 0.028 \\
\hline
\end{tabular}

Data are expressed as mean \pm SD, median (IQR) or $\mathrm{n}(\%)$

*Including sepsis, pulmonary infection, cardiac dysfunction, acute renal failure, re-exploration for bleeding, surgical site infection, stroke, postoperative delirium, paraplegia or paralysis and gastrointestinal bleeding

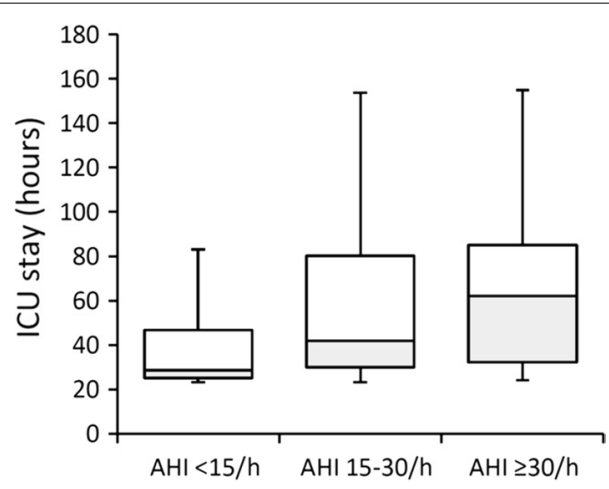

Fig. 2 Length of intensive care unit (ICU) stay stratified by apnoea hypopnea index (AHI)
Here, the high prevalence of OSA in our cohort is in line with previous studies in patients with $\operatorname{AD}[9,10]$. OSA is considered to increase the risk of $\mathrm{AD}$ due to distinctive blood pressure surge and fluctuations, acceleration of atherosclerosis, and uniquely, exaggerated negative thoracic pressure, which induces strong shear forces onto the aorta [27-29]. According to the only literature on the prevalence of TAAD in patients with OSA available as of present [30], middle-aged men with features of being tall, fat and having comorbid hypertension are at high risk of TAAD.

As reported in our previous and present study, many patients with TAAD developed postoperative hypoxaemia, which was closely associated with poor

Table 3 Multivariate logistic analyses of risk factors for postoperative hypoxaemia and a prolonged intensive care unit stay

\begin{tabular}{|c|c|c|c|c|c|c|}
\hline \multirow[t]{2}{*}{ Endpoint/risk factors } & \multicolumn{3}{|c|}{ Univariate analysis } & \multicolumn{3}{|c|}{ Multivariate analysis* } \\
\hline & OR & $95 \% \mathrm{Cl}$ & $p$ value & OR & $95 \% \mathrm{Cl}$ & $p$ value \\
\hline \multicolumn{7}{|l|}{ Postoperative hypoxaemia } \\
\hline Preoperative hypoxaemia (yes vs. no) & 3.54 & $1.34-10.29$ & 0.010 & 3.33 & $1.16-10.52$ & 0.025 \\
\hline Obstructive sleep apnoea (yes vs. no) & 4.42 & $1.66-12.89$ & 0.003 & 3.28 & $1.14-10.10$ & 0.028 \\
\hline $\mathrm{AHI}>30 / \mathrm{h}$ (vs. < 15/h) & 8.64 & $2.14-58.60$ & 0.001 & 6.65 & $1.56-46.26$ & 0.008 \\
\hline \multicolumn{7}{|l|}{ Prolonged intensive care unit stay } \\
\hline Preoperative hypoxaemia (yes vs. no) & 0.76 & $0.29-2.05$ & 0.592 & 0.77 & $0.26-2.28$ & 0.636 \\
\hline Obstructive sleep apnoea (yes vs. no) & 3.84 & $1.32-11.17$ & 0.010 & 4.05 & $1.27-12.90$ & 0.018 \\
\hline $\mathrm{AHI}>30 / \mathrm{h}(\mathrm{vs} .<15 / \mathrm{h})$ & 5.46 & $1.62-18.41$ & 0.005 & 5.58 & $1.54-20.24$ & 0.009 \\
\hline
\end{tabular}

$\mathrm{Cl}$ confidence interval, $\mathrm{OR}$ odds ratio, $\mathrm{AHI}$ apnoea hypopnea index

*Adjusted for age, gender, and body mass index 


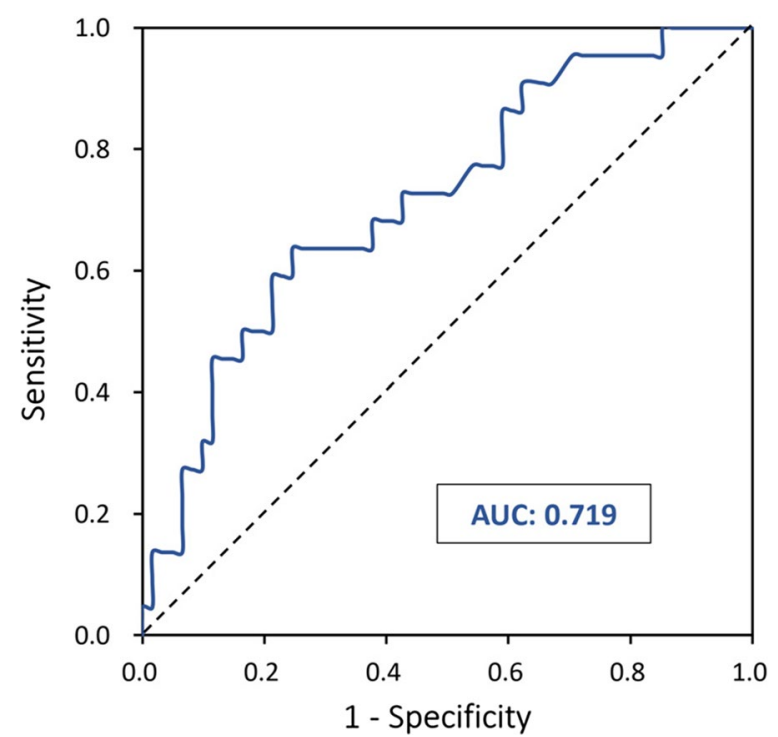

Fig. 3 Receiver-operating characteristic curve of postoperative oxygenation index threshold for predicting prolonged intensive care unit stay. AUC area under the curve

operative outcomes [4-8, 20, 21]. The current study further revealed that OSA was linked to postoperative hypoxaemia, although the underlying mechanisms remain unclear. Upper airway obstruction is less likely to be a reasonable explanation since patients are on mechanical ventilation with tracheal intubation postoperatively. It is not clear whether the postoperative $\mathrm{SaO}_{2}$ reduction was caused by pathological responses secondary to OSA, that is, systemic and pulmonary inflammation [31-33], hypercoagulable state, increased oxygen consumption $[33,34]$, and respiratory muscle fatigue [35]. Memtsoudis et al., found that patients with sleep apnoea had a higher incidence of acute respiratory distress syndrome, a condition of acute hypoxaemia with an $\mathrm{OI}<200$, postoperatively [15]. Therefore, a sleep assessment before major cardiac surgery may be essential for identifying patients at high risk of developing postoperative hypoxaemia, as shown by our results.

Undiagnosed OSA is an incognitive risk factor for prolonged ICU stay following TAAD repair. Although the mechanism has not been elucidated thoroughly, results from previous studies have indicated that OSA is associated with postoperative complications following cardiac and non-cardiac surgeries [12-14], and this could prolong ICU stay and worsen surgical outcomes. The current study shows that severe OSA predicts postoperative hypoxaemia, which in turn is a strong predictor of prolonged ICU stay. Therefore, identification and treatment of preoperative OSA using non-invasive strategies, such as positive airway pressure could lead to a reduced postoperative hypoxaemia and a shorter ICU stay. Unfortunately, most patients with TAAD are in critical condition and need emergency surgery, which renders the evaluation by preoperative polysomnography, impractical. As intermittent desaturation is mainly caused by breathing events, preoperative oximetry is an alternative test that can be easily performed and used to identify patients with high odds of OSA. In addition, the STOPBANG questionnaire is another approach to evaluate OSA, which could also serve as a valuable diagnostic clue considering the high consistency between the STOPBANG score and the results of the sleep test, as shown in our study.

The major limitation of this study is inherent in the nature of TAAD, a clinical catastrophe that has to be managed by an emergency surgery, and this precludes the possibility of having a sleep test before surgical repair. Postoperative sleep assessment together with preoperative questionnaire could still generate incompetent data for determining a preoperative sleep status in individuals with significant changes in body weight and cardiopulmonary function, following an aortic repair. Second, many factors other than OSA can lead to postoperative hypoxaemia and prolonged ICU stay, such as comorbidities, complexity of the procedure and postoperative management. To avoid the risk of model overfitting in statistics, these data were excluded from the multivariate analysis; thus, our conclusion should be extrapolated with caution. This study only included cohorts that underwent a standardised Sun's procedure for TAAD repair [20] and received a similar post operational care by the same professionals, ensuring the comparability among patients.

\section{Conclusions}

The results of this study demonstrate that OSA was highly prevalent in patients with TAAD, and this could predict postoperative hypoxaemia and prolonged ICU stay following surgical repair. Preoperative sleep assessment among patients with AD help identify OSA; further studies are warranted to investigate whether the treatment of OSA benefits the cohort.

\section{Abbreviations}

AD: Aortic dissection; TAAD: Type A aortic dissection; ICU: Intensive care unit; OSA: Obstructive sleep apnoea; AHI: Apnoea hypopnea index; ESS: Epworth Sleepiness Scale; OI: Oxygenation index; BP: Blood pressure; SD: Standard deviation; IQR: Interquartile range; OR: Odds ratio; Cl: Confidence interval; BMI: Body mass index; ROC: Receiver-operating characteristics.

\section{Acknowledgements}

We would like to thank all the patients who participate in this study.

\section{Authors' contributions}

Conception and design: XX, YC, JX, WGM; Administrative support: LZS, YML, JMZ, GFZ; Provision of study materials or patients: YC; Collection and assembly 
of data: $X X, Y C$; Data analysis and interpretation: $X X, W G M$, JX. All authors read and approved the final manuscript.

\section{Funding}

This study was supported by the National Natural Science Foundation of China $(81500037,81970079)$.

\section{Availability of data and materials}

The datasets used and analysed during the current study are available from the corresponding author on reasonable request.

\section{Declarations}

\section{Ethics approval and consent to participate}

All participants provided written informed consent. The study was conducted in accordance with the ethical principles of the Declaration of Helsinki and approved by the Clinical Research Ethics Board of Beijing Anzhen Hospital, Capital Medical University on Aug 28 ${ }^{\text {th }}, 2020$ (Approval number: 2020040X).

\section{Consent for publication}

Not applicable.

\section{Competing interests}

The authors have no conflicts of interest to declare.

\section{Author details}

${ }^{1}$ Sleep Center, Beijing Anzhen Hospital, Capital Medical University, Beijing, China. ${ }^{2}$ Department of Respiratory and Critical Medicine, Beijing Anzhen Hospital, Capital Medical University, No. 2 Anzhen Road, Beijing 100029, China. ${ }^{3}$ Department of Cardiovascular Surgery, Beijing Anzhen Hospital, Capital Medical University, Beijing, China.

Received: 8 January 2021 Accepted: 25 August 2021

Published online: 06 September 2021

\section{References}

1. Evangelista A, Isselbacher EM, Bossone E, Gleason TG, Eusanio MD, Sechtem U, Ehrlich MP, Trimarchi S, Braverman AC, Myrmel T, et al. Insights from the international registry of acute aortic dissection: a 20-year experience of collaborative clinical research. Circulation. 2018;137(17):1846-60.

2. Wu J, Xie E, Qiu J, Huang Y, Jiang W, Zafar MA, Zhang L, Yu C. Subacute/ chronic type A aortic dissection: a retrospective cohort study. Eur J Cardiothorac Surg. 2020;57(2):388-96.

3. Kaji S, Akasaka T, Katayama M, Yamamuro A, Yamabe K, Tamita K, Akiyama M, Watanabe N, Tanemoto K, Morioka S, et al. Prognosis of retrograde dissection from the descending to the ascending aorta. Circulation. 2003;108:300-6.

4. Liu N, Zhang W, Ma W, Shang W, Zheng J, Sun L. Risk factors for hypoxemia following surgical repair of acute type A aortic dissection. Interact Cardiovasc Thorac Surg. 2017;24(2):251-6.

5. Shen Y, Liu C, Fang C, Xi J, Wu S, Pang X, Song G. Oxygenation impairment after total arch replacement with a stented elephant trunk for type-A dissection. J Thorac Cardiovasc Surg. 2018;155(6):2267-74.

6. Jin M, Ma WG, Liu S, Zhu J, Sun L, Lu J, Cheng W. Prolonged mechanical ventilation in adults after acute type-A aortic dissection repair. J Cardiothorac Vasc Anesth. 2017;31(5):1580-7.

7. Li CN, Chen L, Ge YP, Zhu JM, Liu YM, Zheng J, Liu W, Ma WG, Sun LZ. Risk factors for prolonged mechanical ventilation after total aortic arch replacement for acute DeBakey type I aortic dissection. Heart Lung Circ. 2014;23(9):869-74.

8. Ma WG, Chen Y, Zhang W, Li Q, Li JR, Zheng J, Liu YM, Zhu JM, Sun LZ. Extended repair for acute type A aortic dissection: long-term outcomes of the frozen elephant trunk technique beyond 10 years. J Cardiovasc Surg (Torino). 2020;61:292-300.

9. Sampol G, Romero O, Salas A, Tovar JL, Lloberes P, Sagales T, Evangelista A. Obstructive sleep apnea and thoracic aorta dissection. Am J Respir Crit Care Med. 2003;168(12):1528-31.
10. Wang L, Chen J, Li G, Luo S, Wang R, Li W, Zhang J, Liu Y, Huang W, Cao Y, et al. The prevalence of sleep apnea in type $b$ aortic dissection: implications for false lumen thrombosis. Sleep. 2017;40(3):071.

11. Hata M, Yoshitake I, Wakui S, Unosawa S, Takahashi K, Kimura H, Hata H, Shiono M. Sleep disorders and aortic dissection in a working population. Surg Today. 2012;42(4):403-5.

12. Ding N, Ni BQ, Wang H, Ding WX, Xue R, Lin W, Kai Z, Zhang SJ, Zhang XL. Obstructive sleep apnea increases the perioperative risk of cardiac valve replacement surgery: a prospective single-center study. J Clin Sleep Med. 2016;12(10):1331-7.

13. Chan MTV, Wang CY, Seet E, Tam S, Lai HY, Chew EFF, Wu WKK, Cheng BCP, Lam CKM, Short TG, et al. Association of unrecognized obstructive sleep apnea with postoperative cardiovascular events in patients undergoing major noncardiac surgery. JAMA. 2019;321(18):1788-98.

14. Devaraj U, Rajagopala S, Kumar A, Ramachandran P, Devereaux PJ, D'Souza GA. Undiagnosed obstructive sleep apnea and postoperative outcomes: a prospective observational study. Respiration. 2016;94(1):18-25.

15. Memtsoudis S, Liu SS, Ma Y, Chiu YL, Walz JM, Gaber-Baylis LK, Mazumdar M. Perioperative pulmonary outcomes in patients with sleep apnea after noncardiac surgery. Anesth Analg. 2011;112(1):113-21.

16. Kaw R, Pasupuleti V, Walker E, Ramaswamy A, Foldvary-Schafer N. Postoperative complications in patients with obstructive sleep apnea. Chest. 2012;141(2):436-41.

17. Chung F, Abdullah HR, Liao P. STOP-bang questionnaire: a practical approach to screen for obstructive sleep apnea. Chest. 2016;149(3):631-8.

18. Johns MW. A new method for measuring daytime sleepiness: the Epworth sleepiness scale. Sleep. 1991;14(6):540-5.

19. Xia M, Liu S, Ji N, Xu J, Zhou Z, Tong J, Zhang Y. BMI 35 kg/m(2) does not fit everyone: a modified STOP-Bang questionnaire for sleep apnea screening in the Chinese population. Sleep Breath. 2018;22(4):1075-82.

20. Ma WG, Zheng J, Liu YM, Zhu JM, Sun LZ. Dr. Sun's procedure for type A aortic dissection: total arch replacement using tetrafurcate graft with stented elephant trunk implantation. Aorta (Stamford, Conn). 2013;1(1):59-64.

21. Nakajima T, Kawazoe K, Izumoto H, Kataoka T, Niinuma H, Shirahashi N. Risk factors for hypoxemia after surgery for acute type A aortic dissection. Surg Today. 2006;36(8):680-5.

22. Duan XZ, Xu ZY, Lu FL, Han L, Tang YF, Tang H, Liu Y. Inflammation is related to preoperative hypoxemia in patients with acute Stanford type A aortic dissection. J Thorac Dis. 2018;10(3):1628-34.

23. Whelton PK, Carey RM, Aronow WS, Casey DE Jr, Collins KJ, Dennison Himmelfarb C, DePalma SM, Gidding S, Jamerson KA, Jones DW, et al. 2017 ACC/AHA/AAPA/ABC/ACPM/AGS/APhA/ASH/ASPC/NMA/PCNA guideline for the prevention, detection, evaluation, and management of high blood pressure in adults: a report of the American College of Cardiology/American Heart Association Task Force on Clinical Practice Guidelines. J Am Coll Cardiol. 2018;71(19):e127-248.

24. Diab MS, Bilkhu R, Soppa G, Edsell M, Fletcher N, Heiberg J, Royse $C$, Jahangiri $M$. The influence of prolonged intensive care stay on quality of life, recovery, and clinical outcomes following cardiac surgery: a prospective cohort study. J Thorac Cardiovasc Surg. 2017;156(5):1906-1915e19303.

25. Epstein LJ, Kristo D, Strollo PJ Jr, Friedman N, Malhotra A, Patil SP, Ramar K, Rogers R, Schwab RJ, Weaver EM, et al. Clinical guideline for the evaluation, management and long-term care of obstructive sleep apnea in adults. J Clin Sleep Med. 2009;5(3):263-76.

26. Kreibich M, Rylski B, Bavaria JE, Branchetti E, Dohle D, Moeller P, Vallabhajosyula P, Szeto WY, Desai ND. Outcome after operation for aortic dissection type A in morbidly obese patients. Ann Thorac Surg. 2018;106(2):491-7.

27. Marin JM, Agusti A, Villar I, Forner M, Nieto D, Carrizo SJ, Barbe F, Vicente E, Wei Y, Nieto FJ, et al. Association between treated and untreated obstructive sleep apnea and risk of hypertension. JAMA. 2012;307(20):2169-76.

28. Saruhara H, Takata Y, Usui Y, Shiina K, Hashimura Y, Kato K, Asano K, Kawaguchi S, Obitsu Y, Shigematsu H, et al. Obstructive sleep apnea as a potential risk factor for aortic disease. Heart Vessels. 2012;27(2):166-73.

29. Weinreich G, Wessendorf TE, Erdmann T, Moebus S, Dragano N, Lehmann $\mathrm{N}$, Stang A, Roggenbuck U, Bauer M, Jockel KH, et al. Association of obstructive sleep apnoea with subclinical coronary atherosclerosis. Atherosclerosis. 2013:231(2):191-7. 
30. Yanagi H, Imoto K, Suzuki S, Uchida K, Masuda M, Miyashita A. Acute aortic dissection associated with sleep apnea syndrome. Ann Thorac Cardiovasc Surg. 2013;19(6):456-60.

31. Unnikrishnan D, Jun J, Polotsky V. Inflammation in sleep apnea: an update. Rev Endocr Metab Disord. 2015;16(1):25-34.

32. Lavie L. Oxidative stress inflammation and endothelial dysfunction in obstructive sleep apnea. Front Biosci (Elite Ed). 2012:4:1391-403.

33. Budhiraja R, Parthasarathy S, Quan SF. Endothelial dysfunction in obstructive sleep apnea. J Clin Sleep Med. 2007;3(4):409-15.

34. Peng YH, Liao WC, Chung WS, Muo CH, Chu CC, Liu CJ, Kao CH. Association between obstructive sleep apnea and deep vein thrombosis/ pulmonary embolism: a population-based retrospective cohort study. Thromb Res. 2014;134(2):340-5.

35. Blake DW, Chia PH, Donnan G, Williams DL. Preoperative assessment for obstructive sleep apnoea and the prediction of postoperative respiratory obstruction and hypoxaemia. Anaesth Intensive Care. 2008;36(3):379-84.

\section{Publisher's Note}

Springer Nature remains neutral with regard to jurisdictional claims in published maps and institutional affiliations.
Ready to submit your research? Choose BMC and benefit from:

- fast, convenient online submission

- thorough peer review by experienced researchers in your field

- rapid publication on acceptance

- support for research data, including large and complex data types

- gold Open Access which fosters wider collaboration and increased citations

- maximum visibility for your research: over 100M website views per year

At BMC, research is always in progress.

Learn more biomedcentral.com/submissions 